\title{
A BUSINESS ANALYSIS ABOUT “NETFLIX” A GUIDE FOR SENIOR HIGH SCHOOL (SHS) STUDENTS
}

\author{
Dr. Arturo G. Palaming \\ Bautista National High School, Bautista, Pangasinan
}

Article DOI: https://doi.org/10.36713/epra9390

DOI No: 10.36713/epra9390

\begin{abstract}
This report is about an analysis of the Netflix as a popular business ICON nowadays. The analysis focused on the business implications that guides the Senior High School students to consider being an entrepreneur individual. Netflix is a subscription-based streaming service that allows our members to watch TV shows and movies without commercials on an internet-connected device. You can also download TV shows and movies to your iOS, Android, or Windows 10 device and watch without an internet connection.

KEYWORDS: movies, business ICON, broadcast, internet, Senior High School Students, analysis.
\end{abstract}

\section{INTRODUCTION}

Since the 1960s, television broadcast was the most common way of distributing video content but that dominance of broadcast television has come to its end. With the emergence of the internet, streaming services, and the general evolution of digital technologies, media powerhouses started to discover newer ways of delivering videos. On one hand, consumers were tired of being limited by restrictions of TV broadcasts and physical mediums like DVDs. Eventually, this soon evolved to the rise of VOD on Connected-TV, mobile, and desktop platforms. The video on demand (VOD) industry soon began to grow. People preferred to watch their online videos when and wherever they chose to. In a recent report, they found video viewing on VOD platforms "[is] up $155 \%$ yearover-year, with an average viewing time of 17.1 minutes per session," and businesses are taking advantage of this trend. In that report they indicated that, the video streaming market is predicted to grow by $\$ 149.96$ billion, by 2024 . By 2028 , video streaming will be worth $\$ 223.98$ billion. ${ }^{1}$

But what exactly is VOD? VOD, or video-ondemand, is any content distribution platform that gives

\footnotetext{
${ }^{1}$ The "Global Video-on-demand (VOD) Market 2021 2025" report on Research And Markets.com's , Dec. 14, 2021 (GLOBE NEWSWIRE)
}

viewers the ability to choose when, where, and how they view media. Netflix is one such platform. Netflix streams via internet, it doesn't rely on cable or satellite connections to get their material out. When compared to traditional broadcast television or cable TV, Netflix has 3 core components viewers prefer: 1.) Subscribers can watch material at any time of day, 2.) Subscribers can pick and choose any material they wish to watch. 3.) and lastly, subscribers use media controls like play, pause, rewind, fast forward, and can completely control how they watch content. Viewing content has now become convenient and easily accessible.

Netflix, a SVOD (Subscription Video-OnDemand), whose competitors are Amazon Prime, Disney+, Apple TV+, HBO Max and Hulu, gives viewers full access to a video library for a subscription fee. These paid subscriptions give viewers all their favorite content on one platform with no ads or popups. $^{2}$

\section{PROFILE}

Gone are the days where we needed to schedule our days around our favorite TV programs and movies or those blockbuster days with family or friends, when

\footnotetext{
${ }^{2}$ The Difference Between SVOD, AVOD, and Other Video-On-Demand Services, Aug 19, 2020, ALLROLL
} 
we rented out a movie VHS/VCR/DVD from the neighbor-hood video store while dreading the due date notices and late fees when videos where not returned on time. Video on demand (VOD) revolutionized the way video content is viewed and has brought traditional broadcast television and cable TV to the next level thanks to the widespread availability of high-speed broadband internet.

Netflix is an American multinational entertainment company founded on 29 August 1997 in Scotts Valley, California. by Reed Hastings and Marc Randolph. It specializes and provides streaming media and video on demand both online and physically, and has recently become a film and television producer, as well as online distributor.

From relatively humble beginnings as a DVDby-mail service, Netflix has grown into one of the most used video streaming services in the world. The company was one of the first to see the potential of video streaming technology and began to transition to a subscription video-on-demand model in 2007. Since this transition, Netflix's revenue has grown from 1.36 billion to around 25 billion in just 12 years. The number of Netflix subscribers has followed a similar trend, increasing from less than 22 million in 2011 to nearly 214 million in 2021. 3 When the pandemic swept the world in 2020, VOD suddenly became a service people couldn't live without. Public lockdowns drove attention online as people searched for ways to occupy time and fulfill basic needs from home. The Pandemic definitely accelerated what was already happening.

\section{ANALYSIS AND REACTION}

It was in the latter half of the 1990, when Netflix faced one of its most trying times, the dot-com bubble burst and venture funding was wiped out. Netflix was faced with the painful decision to terminate a third of its workforce just to keep the business afloat. Reed Hastings then CEO knew that morale would sink and the company would go belly up.

$\mathrm{He}$ was surprised however to witness what happened next, He saw that despite the retrenchment more work was accomplished and employees seemed more eager and committed about their work. It dawned on him that by keeping the high performers and removing the "non-performing assets" things began to change.

\footnotetext{
${ }^{3}$ STATISTA: Netflix - Statistics \& Facts Published by Julia Stoll , Nov 11, 2021
}

In a book authored by him and Erin Meyer, he speaks of Netflix Transformative Period in No Rules: Netflix and the Culture of Reinvention. Here he stated that Netflix doesn't want its leaders to make all the big decisions and control every high-stakes situation for their direct reports. It wants them to lay out the context, so that employees feel empowered and informed to make the judgment call themselves - even when there's millions of dollars on the line. ${ }^{4}$

This we learned became the foundation of much that has led to Netflix's success. He spoke on the importance hiring high performers, giving them lots of transparency and freedom, and shedding away any rules that might get in the way. The innovative spirit of Netflix is largely due to the 7 leadership initiatives that defines Netflix's organizational culture :

Getting Employee Feedback is high on their list of priorities. Anytime, Anywhere. Most people are reluctant to give constructive criticism to their colleagues, much more their bosses but in Netflix, they seek this type of exchange. The culture of openness and feedback is given with positive intent and provides an alternative solution The impact of the culture of feedback prevents an escalation of a situation and team members are able deal fairly and openly with each other in a less threatening environment. ${ }^{5}$

In promoting this kind of environment Hastings says plainly that the company needs to get rid of the "jerks." Egos have no place in Netflix.

1. It was important to Pay People More Than They Expected Netflix believes that, to attract and retain the top talent, it has to pay them more than their competitors do. Employees where encouraged to accept job interview from their competitors so that salary rates are actually gathered and divulged to HR. That way NETFLIX was in a better position to negotiate higher salaries with their employees.

2. Trusting People Is Worth the Risk Hastings contends that, when you give employees access to information that is typically reserved for senior executives, they feel a higher sense of ownership and responsibility. Keeping secrets is off-limits at Netflix.

3. Champion the Brilliant Idea Your Boss Hates Push back against a strong and publicly stated opinion from the top management to rally excitement for an

\footnotetext{
${ }^{4}$ No Rules: Netflix and the Culture of Reinvention by Reed Hastings, and Erin Meyer

${ }^{5}$ We Are Netflix Podcast: Episode 2 - Netflix Culture \& How We Hire at Netflix - YouTube, May 31, 2018
} 
idea you support. Having a voice and making yourself heard is important.

4. 'Sunshine' Your Failures That means, if you're a Netflix employee, and your project or idea crashes and burns, you have to share with the company your comprehensive assessment of what went wrong and what you learned. Accountability and taking responsibility for their failure, is ingrained in them very early on.

5. Practice the 'Keeper Test' Hastings and McCord learned something valuable in the early days, when they saw Netflix's culture turn around the most effective way for them to innovate was to keep only "the keepers." thus "Keeper Test." Often times employees are told "We are a team, not a family. This was to prevent employees from competing with each other in an unhealthy way. Worthy to note is that in Netflix there is no firing quota or rating system. Managers are just tasked to terminate inadequate performers.

6. Context Is More Important Than Direction. Netflix doesn't want its leaders to make all the big decisions and control every high-stakes situation for their direct reports. It wants them to lay out the context, so that employees feel empowered and informed to make the judgment call themselves - even when there's millions of dollars on the line.

\section{BUSINESS IMPLICATION}

For many CEOs, making most of the major decisions and settling the tough call is what it means to be a leader. For Hastings, he saw things differently sharing in the decision making, while letting his team dream up new products and initiatives was what he was all about. What he really cared about was working with incredible talented people that can drive the company. Based on his leadership initiatives freedom and responsibility and high performance culture was what he believed in. In so doing Netflix game plan was to:

Always Stay Ahead of the Competition. When Netflix was founded in 1997, Americans who wanted to watch a movie went to a video store, rented a DVD or VHS tape, and avoided late fees by returning them on time. Hastings then realized the cost of sending plastic disc which had room for a huge amount of data and weighs next to nothing, was feasible. Thus distribution of movies on DVDs by mail. The idea caught on and the rest is history. For blockbuster, their primary competitor, it was the beginning of their end.

For Employees: Freedom and Responsibility Always go together Its part of the Netflix culture. Mistakes always need to be a learning experience for everyone. Because of the culture of high performance, there was always a high turnover of people. Hastings in an interview at Stanford University said that with adequate performance comes a generous severance package. ${ }^{6}$

Realize that bigger isn't Always worse. People need to fight the notion that as a company grows bigger, the culture gets worse. At Netflix, they are with the mindset that they are significantly better because of its strong foundation and values but more so because they have more brains thinking about the problem. If you have more thoughtful people thinking about how to improve, they will make a lot more progress. Hasting attributes these thoughts to the first 86 pages of the book of Jim Collins on Beyond Entrepreneurship. ${ }^{7}$

You don't have to Always be like Steve Jobs to be a great CEO. There is this notion that to be a great $\mathrm{CEO}$ you have to be a great product person just like Steve Jobs. That is not necessarily true. That develops a whole lot of dependence on the CEO. That can't be fun. Hasting said that Netflix builds a strong set of independent innovative great thinkers. We hire only the best. With the culture of constant feedback, we tap into a wealth of diverse and limitless potential.

Don't Always make your process "dummy-proof." Companies do not always need to have processes for everything they do nor do they always have to dummy proof them. By doing so you only get dummies working in those companies. In complete contrast to that, Netflix focuses on giving people great freedom and responsibility. Employees will make mistakes, "Sunshine it" but will always get a lot of great ideas stemming from it too.

Being aggressive is not Always good, it can lead to mistakes. Timing is everything. Netflix made a radical change in its business model in 2009, separating the mail-order business from the streaming business. This amounted to a rate increase of about $60 \%$. Consumers did not look to kindly to it, the stock market hated it, and the company quickly backed off. ${ }^{8}$

\footnotetext{
${ }^{6}$ We Are Netflix Podcast: Episode 2 - Netflix Culture \& How We Hire at Netflix - YouTube May 31, 2018

7 Beyond Entrepreneurship: Turning Your Business into an Enduring Great Company

by James C. Collins and William C. Lazier, March 1992
}

${ }^{8}$ Reed Hastings, Netflix: Stanford GSB 2014

Entrepreneurial Company of the Year

Oct 16, 2014 


\section{CONCLUSION}

I can only surmise that subscriptions to NETFLIX will only increase and continue to grow. It is not farfetched but is actually expected since NETFLIX is more a fit to the global audiences' needs convenience, choice, and cost. NETFLIX has achieved all this and more. Offering services ahead of the pack has made them a global leader in this industry. In fact, because of the pandemic, we have become more "internet-centric and video dependent that I believe most businesses and marketing professionals will plan to devote more money to video in the future. So what does Netflix need to do to stay ahead? I think their organizational culture, although unorthodox works for them. They just need to continue doing what they are doing because that is a business model that works for them. They have very successful thus far.

Netflix has always been ahead of the pack in terms of what they have to offer. The best way for their business to continue to thrive is to quickly adapt to the market trends. We already know that this industry will be big in the next 5 years so what they need to do is to stay ahead of their competitors in everything, including the services that they offer. Use the same strategies that kept them ahead when the introduced new products in the 90s. They need to stay on the cutting edge by using popular strategies they used in the past, such as:

Personalization: The use of audience data analytics and how they reached out to their viewers to learn what types of video they want more of. Netflix's key to business longevity is their awareness and understanding of who their customers are and what their customers want.

Mobile use: They need to Optimize content for people who are watching from their mobile devices globally (that's where over $75 \%$ of video is consumed.) Accessibility, ease and Cost effectiveness was what sold them to their subscribers. They can do the same with the global mobile users.

Keep Up with Their Content and Quality: Build a strong Video Library. Their video has to add value. NETFLIX is very big on marketing and putting their name out there. They can continue to offer just enough to entice users to sign up. Their trial promos were always a winner for them.

\section{RECOMMENDATION}

1. Senior High School students should consider Netflix to be a focal point of business interest in the near future.
2. Netflix caters the convenient of their viewers, therefore they should have to consider kind of movies that they are going to sell in their network.

3. In order for the future to remains bright, as a trends indicate that the demand for video should be continue to grow - in fact, it is not at all surprising because Netflix's audience needs and lifestyles have not changed.

4. In 2022 onwards people should still be looking at convenience, choice, and cost. Netflix offers all that and more. Though some analysts may believe that it has saturated its own home market they may now be looking at capitalizing in on the Asian Market. One great initiative I noticed was how Netflix tapped into the International Market by offering Local content to its subscribers. Korean Dramas (Crash Landing on you), Spanish Movies (Money Heist) French movies (Lupin) and even Filipino movies (The Promise).

5. This is definitely the way to go in winning over consumers where the brand is still not widely used. Through that push we are already seeing crossovers with local content being a global phenomenon. Case in point are the K dramas. More Netflix Movies to choose from. 